\title{
Nicolai Hartmann: Reality, Modality, and Value Editor's Introduction
}

\author{
Keith R. Peterson ${ }^{1}$
}

Received: 31 January 2017/Accepted: 16 February 2017/Published online: 22 February 2017

(C) Springer Science+Business Media Dordrecht 2017

The papers collected in this issue aim to contribute to the growing international discussion of the wide-ranging work of early twentieth century German philosopher Nicolai Hartmann. With the exception of the included translation and its accompanying introduction, earlier versions of the essays gathered here were first presented at a Nicolai Hartmann Society panel on Hartmann's work at the 54th meeting of the Society for Phenomenology and Existential Philosophy (SPEP), the second largest philosophy organization in North America, on October 8, 2015 in Atlanta, Georgia, USA. Organized by the current president of the NHS, Keith Peterson (Colby College, Waterville, Maine, USA), this was the third such panel at a major US conference in the past 4 years. Previous panels were organized by Eugene Kelly at the American Philosophical Association Central Division meeting in February, 2013 in New Orleans, Louisiana, as well as the 51st SPEP conference in Rochester, New York, in 2012, organized by Peterson. In 2014, the most recent independent meeting of the NHS was held in Trento, Italy, and a number of papers were collected in a volume of conference proceedings and published by Walter de Gruyter in January of 2016, titled New Research on the Philosophy of Nicolai Hartmann and edited by Keith Peterson and Roberto Poli (former president of the NHS). The NHS is looking forward to organizing more smaller panels, and to a joint conference with the Max Scheler Society and Helmuth Plessner Gesellschaft in Köln, Germany, in 2019.

The papers here are primarily aimed at generating further discussion on Hartmann's work, as is appropriate for papers originally presented at a conference. They more often suggest new directions and connections than follow them through in a detailed and sustained way. They show their origins as conference papers, and are not in any way intended as the final word on the central themes of "Reality,

Keith R. Peterson

krpeters@colby.edu

1 Colby College, Waterville, ME, USA 
Modality, and Value" in Hartmann's immense corpus. Additionally, an exchange highlighting a recently published book in English on Hartmann by Predrag Cicovacki, entitled The Analysis of Wonder (Bloomsbury 2014), is included here. There are two more pieces included in this issue of Axiomathes that were not presented at the 2015 SPEP conference but which should enrich the discussion of Hartmann. One is the translation of Hartmann's 1937 essay “The Megarian and the Aristotelian Concept of Possibility: A Contribution to the History of the Ontological Problem of Modality," translated by Frederic Tremblay and Keith Peterson, and an "Introduction to Nicolai Hartmann's 'The Megarian and Aristotelian Concept of Possibility", accompanies it, written by Tremblay.

Each of the first three essays explores aspects of Hartmann's philosophy not often (if at all) dealt with in recent literature on Hartmann, and works to bring it into dialogue with contemporary trends or historical figures. The first paper by Tremblay, "Vladimir Solovyov, Nicolai Hartmann, and Levels of Reality," brings the Baltic-German Hartmann's work into conversation with Russian philosophers of the late nineteenth and early twentieth centuries, a connection which has been under-researched in Hartmann scholarship to say the least. It argues that since Hartmann studied with and was influenced by Nikolai Lossky, and Lossky has a theory of "levels of reality" that he adopted from Vladimir Solovyov, it may be important to find out whether and to what extent Hartmann's theory of levels of reality was impacted by Solovyov's ideas. Solovyov had a five level hierarchy in contrast to Hartmann's four, but the theory appears to share significant similarities with the theory of levels that Hartmann will develop a few decades later. Since Solovyov's work was well known in Russia, it would be unlikely that Hartmann was not acquainted with his work, and chances are that Hartmann came into contact with it in some detail. An intellectual lineage could thus likely be traced from Hartmann back to Solovyov, in addition to the other thinkers Hartmann himself identifies as sources for his ideas concerning levels of reality, including Plato, Aristotle, and Plotinus.

Both the translation of Hartmann's 1937 article and the essay by Stephanie Adair, co-translator with Alex Scott of Hartmann's massive Possibility and Actuality (Walter de Gruyter 2013), deal with the theme of ontological modality. Adair explores the peculiar modal nature of aesthetic objects as Hartmann discusses them in Possibility and Actuality, where an apparent "modal imbalance" inherent in aesthetic objects might be taken to violate the "intermodal laws of the real" that Hartmann details in that text. She explains these real intermodal laws and describes how they give the "real sphere" its characteristic determinateness, and continues to explain how artistic objects seem to entail a kind of possibility that extends beyond "real necessity," an otherwise impossible occurrence for the real sphere. She argues that because only the foreground layer of the aesthetic object is fully situated within the real sphere of being, and its background layer has components that belong to the ideal sphere, two sets of intermodal laws apply to such objects. In the ideal sphere, "the law of intermodal implication only holds in one direction so that what is necessary must be actual and what is actual must be possible." Unlike the real sphere, this relation of implication is not reciprocal for the ideal modes, so "ideal possibility" implies neither "ideal actuality" nor "ideal necessity." This means that 
there is an effective "deactualization" of the foreground, allowing the ideal contents in the background to take precedence and exhibit the "immense freedom of the artistically possible."

While Adair's contribution touches on aesthetic value, the connection between moral and aesthetic values is a larger theme of Cicovacki's 2014 book on Hartmann, The Analysis of Wonder. It has the virtue of trying to achieve a synoptic view of Hartmann's incredibly wide philosophical output that does not simplify, and dwells mainly on his ontology and value theory. The sections on real being (Part I) and ideal being (Part II) are synthesized in the section on human personality (Part III), which is seen as the hinge or articulation-point of the two spheres. Eric Chelstrom's criticisms of the book turn on Cicovacki's emphasis on Hartmann's account of the importance of a loving attitude and Hartmann's theory of personality, in addition to some less substantive issues of framing with reference to Kant, post-modernism, existentialism, Hannah Arendt, and the theme of "wonder" itself. Cicovacki defends his reading of Hartmann, and claims that while Hartmann himself does not sufficiently develop either his conception of love or his understanding of personality, both conceptions could be further elaborated and serve as ways to reintroduce Hartmann into the mainstream of current philosophical discussion.

Peterson's contribution also attempts to insert Hartmann's ideas into the mainstream of current philosophical discussion. He argues that Hartmann's works provide some of the richest resources upon which recent realists might draw for both inspiration and argument. After introducing some key concepts and arguments from a few of the players in the recent "ontological turn" in contemporary "Continental" philosophy, including Quentin Meillassoux, Ray Brassier, and Maurizio Ferraris, he argues that many of them were already clearly articulated in Hartmann's works. Here he shows that Hartmann too had an early critique of "correlationism" in philosophy, as well as a conception of the "unamendability" or "hardness" of the real. In the last part of the paper he describes and comments on Hartmann's original and innovative arguments concerning the much debated "thing in itself," which he considers a key "critical" concept of his new ontology. Hartmann's treatment of this issue demonstrates the sophistication-and, perhaps, superiority-of Hartmann's approach to a realist ontology.

We hope that these small additions to the growing Hartmann literature are enticements and provocations to further study and exploration of Hartmann's vast corpus. 